\title{
Repellent Guidance of Regenerating Optic Axons by Chondroitin Sulfate Glycosaminoglycans in Zebrafish
}

\author{
Catherina G. Becker and Thomas Becker \\ Zentrum für Molekulare Neurobiologie Hamburg, Universität Hamburg, D-20246 Hamburg, Germany
}

We analyzed the role of chondroitin sulfate (CS) glycosaminoglycans, putative inhibitors of axonal regeneration in mammals, in the regenerating visual pathway of adult zebrafish. In the adult, CS immunoreactivity was not detectable before or after an optic nerve crush in the optic nerve and tract but was constitutively present in developing and adult nonretinorecipient pretectal brain nuclei, where CSs may form a boundary preventing regenerating optic fibers from growing into these inappropriate locations. Enzymatic removal of CSs by chondroitinase $A B C$ after optic nerve crush significantly increased the number of animals showing erroneous growth of optic axons into the nonretinorecipient magnocellular superficial/ posterior pretectal nucleus ( $83 \%$ vs $42 \%$ in controls). In vitro, a substrate border of CSs, but not heparan sulfates, strongly repelled regenerating retinal axons from adult zebrafish. We conclude that CSs contribute to repellent axon guidance during regeneration of the optic projection in zebrafish.

Key words: CNS regeneration; extracellular matrix; chondroitin sulfate proteoglycans; heparan sulfate; chondroitinase $A B C$; tenascin-R; retinal ganglion cell axons; neurite outgrowth
Fish and amphibians, in contrast to mammals, are capable of regenerating lesioned axon tracts in the adult CNS (for review, see Martin et al., 1994; Bernhardt, 1999). Regenerative failure of mammalian CNS axons is, at least in part, attributed to inhibitory molecules that are expressed by glial cells (for review, see Fawcett and Geller, 1998; Qiu et al., 2000). Expression of chondroitin sulfate (CS)-carrying proteoglycans (CSPGs) is increased in a CNS lesion site, where these molecules may form a barrier to regrowing axons (for review, see Fawcett and Asher, 1999; Bovolenta and Fernaud-Espinosa, 2000). CSs contribute to this inhibition, because treatment of lesion sites with chondroitinase renders these more supportive to axon growth in vitro (McKeon et al., 1995; Zuo et al., 1998) and in vivo (Yick et al., 2000; Moon et al., 2001).

During development, CSs (and also their core proteins; Dou and Levine, 1994; Garwood et al., 1999) play a complex role in axon guidance (for review see Silver, 1994). Application of chondroitinase or purified CSs alters the route of optic axons (Brittis et al., 1992; Chung et al., 2000) and other axons (Anderson et al., 1998; Bernhardt and Schachner, 2000). Although in some systems, CSs appear to exclude axons, suggesting a repelling function for axons (Snow et al., 1990; Oakley and Tosney, 1991; for review, see Faissner and Steindler, 1995), in others, axons appear to prefer CS substrates (Bicknese et al., 1994; Faissner et al., 1994). In yet others, there is a complex distribution of CSs in the pathway of growing axons (Fernaud-Espinosa et al., 1996; Wilson and Snow, 2000), which led to the suggestion that CSs may anchor other molecules that guide axons in the extracellular matrix

\footnotetext{
Received Aug. 20, 2001; revised Nov. 2, 2001; accepted Nov. 6, 2001.

This work was supported by Deutsche Forschungsgemeinschaft Grants Be1654/3 and Be1650/3-1. We thank Dr. Melitta Schachner for support, Drs. Melitta Schachner, Mario F. Wullimann, and Udo Bartsch for helpful suggestions and critically reading this manuscript, Dr. Alexander Dityatev for help with statistical analyses, and Vladimir Sytnyk for introduction to the confocal microscope.

Correspondence should be addressed to Dr. Catherina G. Becker, Zentrum für Molekulare Neurobiologie Hamburg, Universität Hamburg, Martinistrasse 52, D-20246 Hamburg, Germany. E-mail: tcbecker@zmnh.uni-hamburg.de. Copyright (C) 2002 Society for Neuroscience $0270-6474 / 02 / 220842-12 \$ 15.00 / 0$
}

(Emerling and Lander, 1996). Finally, in vitro experiments indicate that reactions of developing axons to CSs depend on the mode by which the glycans are presented (soluble, homogeneous, or as a step gradient; Snow and Letourneau, 1992; Challacombe and Elam, 1997; Hynds and Snow, 1999), on the composition of CS side chains (Faissner et al., 1994; Braunewell et al., 1995; Clement et al., 1998; Nadanaka et al., 1998), and on the neuronal cell type analyzed (Snow and Letourneau, 1992; FernaudEspinosa et al., 1994; Dou and Levine, 1995).

The optic projection of adult zebrafish regenerates spontaneously after a lesion and precisely reinnervates its former targets in the brain (C. G. Becker et al., 2000). The optic projection of teleost fish, including zebrafish (Marcus et al., 1999), is continuously growing, such that positive (adhesive and attractive) and negative (repellent and inhibitory) guidance molecules that are developmentally downregulated in mammals are still present in the adult fish brain (C. G. Becker et al., 2000; Petrausch et al., 2000). These molecules supposedly guide newly growing and regenerating optic axons to their correct targets.

We show here that digestion of constitutively present CSs in nonretinorecipient pretectal nuclei increases invasion of these nuclei by regenerating optic axons in adult zebrafish. A boundary of CSs in vitro repels retinal axons. This indicates a repellent guidance function of CSs for optic axons.

\section{MATERIALS AND METHODS}

\section{Animals}

Adult (body length $>2 \mathrm{~cm}$, age $>4$ months) and developing (age $5 \mathrm{~d}$ to 4 weeks) zebrafish, Danio rerio, were taken from our breeding colony or bought at a local pet shop. Before surgery, adult fish were maintained in groups of 10 animals at a 14/10 hr light/dark cycle and a temperature of $27^{\circ} \mathrm{C}$. After surgery, individual fish were kept in 21 tanks. Fish were fed dried fish food and live brine shrimp. All animal experiments were approved by the University and State of Hamburg animal care committees and conformed to National Institutes of Health guidelines.

\section{Reagents}

To detect CSs, we used the CS-56 antibody (Sigma, Deisenhofen, Germany), which recognizes chondroitin-4 sulfate and chondroitin-6 sulfate 
(Avnur and Geiger, 1984). The antigen of the CS-56 antibody is liable to digestion with purified protease-free chondroitin sulfate ABClyase (chondroitinase, EC 4.2.2.4; Saikagaku, Tokyo, Japan), which was used in this study for in vivo and in vitro experiments. As an additional enzyme for in vivo experiments, we used heparinase III (heparinase, EC 4.2.2.8; Sigma). Antibody 2B6 (Saikagaku) was used to detect "sugar stub" neoepitopes created by chondroitinase treatment in immunohistochemistry (Moon et al., 2001). Tenascin-R was detected with the mouse monoclonal antibody 597 (Pesheva et al., 1989).

\section{Immunohistochemistry combined with tracing of optic axons}

Fluorescence immunolabeling of a 14- $\mu$ m-thick cryosection of freshfrozen adult and larval tissues was performed as described previously (Becker et al., 1995). Binding of primary antibodies was detected with the appropriate Cy3-labeled secondary antibodies (Dianova, Hamburg, Germany). The specificity of CS labeling was tested by removing the antigen before staining with chondroitinase (Becker et al., 1995). This treatment completely abolished labeling of CS-56 in the nonretinorecipient pretectal brain nuclei (see Results). Fluorescence intensity was measured using University of Texas Health Science Center (San Antonio, TX) Image Tools for Windows.

For simultaneous visualization of the optic projection and CS distribution, optic nerves were labeled with biocytin (see below). Animals were perfused with $4 \%$ paraformaldehyde, and their brains were embedded in $4 \%$ agar and sectioned at $40 \mu \mathrm{m}$ with a vibratome (Leica, Hamburg, Germany). Biocytin was detected with Cy2-coupled streptavidin (Dianova); CSs were detected using the CS-56 antibody and a Cy3-coupled secondary antibody (Dianova). The sections were mounted in Moviol (Merck, Darmstadt, Germany) and viewed under a laser scanning microscope (Zeiss, Oberkochen, Germany) using argon and krypton lasers, with appropriate emission and detection wavelengths.

\section{Organotypic retinal cell culture}

Preparation of in vitro substrates. Substrates were prepared similarly to a previously published protocol (Becker et al., 1999). All solutions were prepared in PBS; all incubations were performed at room temperature; and all washes were done three times in PBS, unless indicated differently. Tissue culture wells $(35 \mathrm{~mm})$ with a glass bottom (MatTek, Ashland, MA) were coated with poly-D-lysine $(0.05 \%$ in $0.5 \mathrm{M}$ borate buffer) for 2 hr, washed, and air-dried. Wells were then incubated with nitrocellulose dissolved in methanol according to the method of Lagenaur and Lemmon (1987). Wells were again coated with poly-D-lysine for $2 \mathrm{hr}$, washed, and air-dried. A mixture of CSs A, B, and C (100 $\mu \mathrm{g} / \mathrm{ml}$; Sigma) or heparan sulfates (HSs, $100 \mu \mathrm{g} / \mathrm{ml}$; Sigma) were mixed with rhodaminedextran $(1 \mathrm{mg} / \mathrm{ml}$; Molecular Probes, Eugene, OR) and spotted as $8 \mu \mathrm{l}$ droplets at $4^{\circ} \mathrm{C}$ overnight. After washing, laminin (Sigma) was coated on the surface of the entire well at a concentration of $1.7 \mu \mathrm{g} / \mathrm{ml}$ at $4^{\circ} \mathrm{C}$ overnight. Wells were washed and immediately used for explant culture. Test substrates were never allowed to dry out throughout the coating procedure.

Efficient coating of CSs, HSs, and laminin was demonstrated by immunolabeling of substrate spots on cell culture surfaces at the end of cell culture experiments. CS immunoreactivity was liable to chondroitinase digestion. Immunolabeling for laminin showed homogeneous coating on the test substrate spot and next to it (data not shown).

Retinal explant culture. Animals received a bilateral conditioning optic nerve crush $7 \mathrm{~d}$ before retinal explant preparation, as published previously for serum-free amphibian retinal explant culture (Becker et al., 1999). Animals were deeply anesthetized and decapitated, and the eyes were collected in HBSS. Eyes were quickly rinsed in $70 \%$ ethanol, and the retinas were dissected and chopped into $400 \times 400 \mu \mathrm{m}$ squares on a tissue chopper (McIlwain, Gomshall, UK). Squares were washed in HBSS and L-15 tissue culture medium (Invitrogen, Karlsruhe, Germany) containing N2 supplements (Sigma) and transferred to a medium-filled tissue culture well. Explants were oriented with fine forceps to attach them to the culture substratum with the vitreous side down next to the substrate border. Culture wells were placed in a humidified chamber, and neurites were allowed to grow out at $26^{\circ} \mathrm{C}$ for $3-4 \mathrm{~d}$.

Quantification of border interactions. The effect of substrate borders on axon outgrowth from retinal explants was quantified as described previously (Becker et al., 1999, T. Becker et al., 2000). Because fascicles accumulated at the border at the end of the incubation period ( $3-4 \mathrm{~d}$; see Fig. 4A), interactions of individual fascicles with the substrate border could not be counted. Therefore, border interactions were scored for whole explants. Explants for which virtually all axon fascicles were

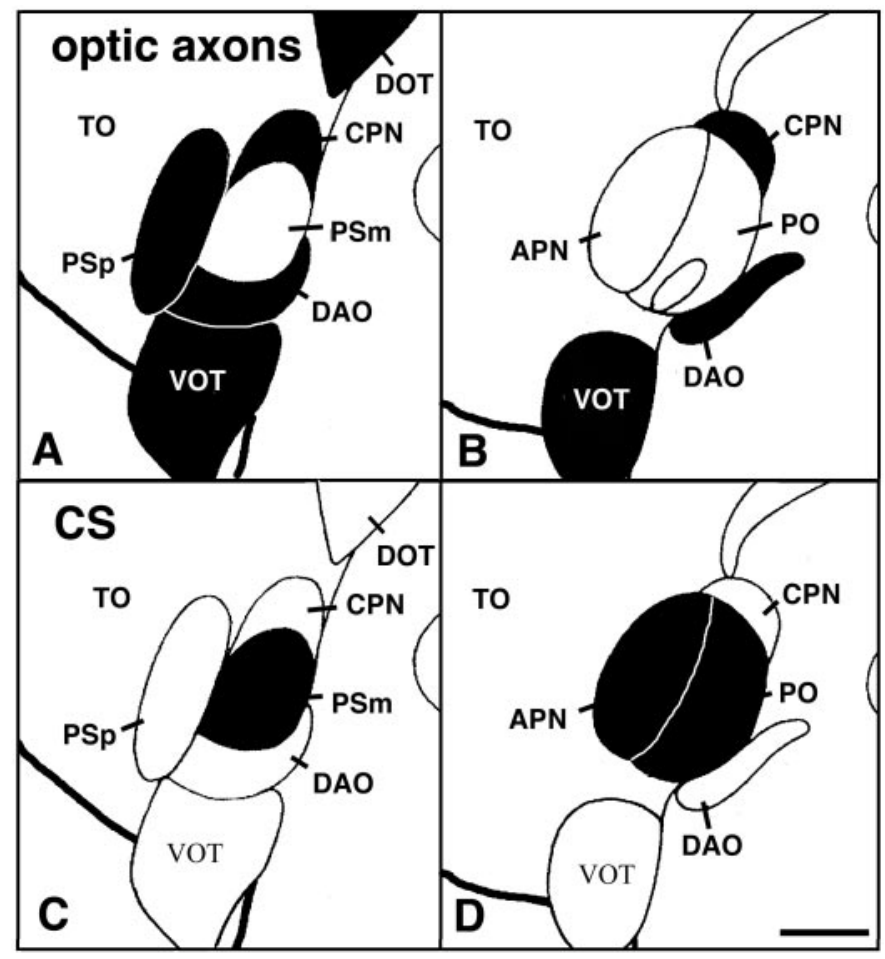

Figure 1. Semischematic representation of the distribution of optic fibers $(A, B)$ and $C S(C, D)$ in the pretectum of adult zebrafish. The same two consecutive transverse sections are shown in $A$ and $B$ and $C$ and $D$; dorsal is at the top; lateral is left. $A$ and $C$ are $60 \mu \mathrm{m}$ rostral to $B$ and $D$. The presence of optic fibers in $A$ and $B$ and CS immunoreactivity in $C$ and $D$ is indicated by black filling of brain structures. Optic fibers are present in the parvocellular superficial pretectal nucleus $(P S p)$, the central pretectal nucleus $(C P N)$, the dorsal accessory optic nucleus $(D A O)$; the optic tectum ( $T O$; innervation not indicated), and the ventral optic tract (VOT) and dorsal optic tract $(D O T)$. The magnocellular superficial pretectal nucleus $(P S m)$, the accessory pretectal nucleus $(A P N)$, and the posterior pretectal nucleus $(P O)$ are free of optic fibers but are strongly CS immunopositive. Outlines of brain nuclei are taken from Wullimann et al (1996). Scale bar, $100 \mu \mathrm{m}$.

prevented from crossing the substrate border at the end of the incubation period were counted and expressed as a percentage of all explants extending axon fascicles that contacted the substrate border.

\section{Optic nerve crush and in vivo injections of chondroitinase}

For optic nerve lesions of adult zebrafish, individuals were anesthetized by immersion in $0.033 \%$ aminobenzoic acid ethylmethylester (MS222; Sigma) for $5 \mathrm{~min}$. One eye was gently lifted from its socket, and the exposed optic nerve was crushed behind the eyeball under visual control using watchmaker's forceps as described previously (C. G. Becker et al., 2000). At 6 and $13 \mathrm{~d}$ after the lesion, animals were reanesthetized; a small part of the skull overlying the tectum was removed; and $\sim 0.3 \mu \mathrm{l}$ of chondroitinase $(2 \mathrm{U} / \mathrm{ml}$ in $50 \mathrm{~mm}$ Tris- $\mathrm{HCl}, 60 \mathrm{~mm} \mathrm{Na}$-acetate, and $0.1 \%$ bovine serum albumin, $\mathrm{pH}$ 7.86) was injected into the third ventricle using a glass needle attached to a micromanipulator. Control animals received either only an optic nerve crush or injections of either vehicle or $2 \mathrm{U} / \mathrm{ml}$ heparinase III at 6 and $13 \mathrm{~d}$ after optic nerve crush. As a rule, animals were processed for tracing of regenerated optic fibers at $24 \mathrm{~d}$ after the lesion if not indicated otherwise.

\section{Tracing}

Tracing of optic axons with biocytin was done as described previously (C. G. Becker et al., 2000). Briefly, small pieces of gelatin foam (Gelfoam; Upjohn, Kalamazoo, MI) soaked with biocytin (Sigma) were prepared. Fish were anesthetized, and the nerve was exposed as described for the crush. To apply the Gelfoam pledget, the nerve was cut, and the pledget was immediately positioned at the stump of the optic nerve attached to the brain. The tracer was allowed to be transported for 


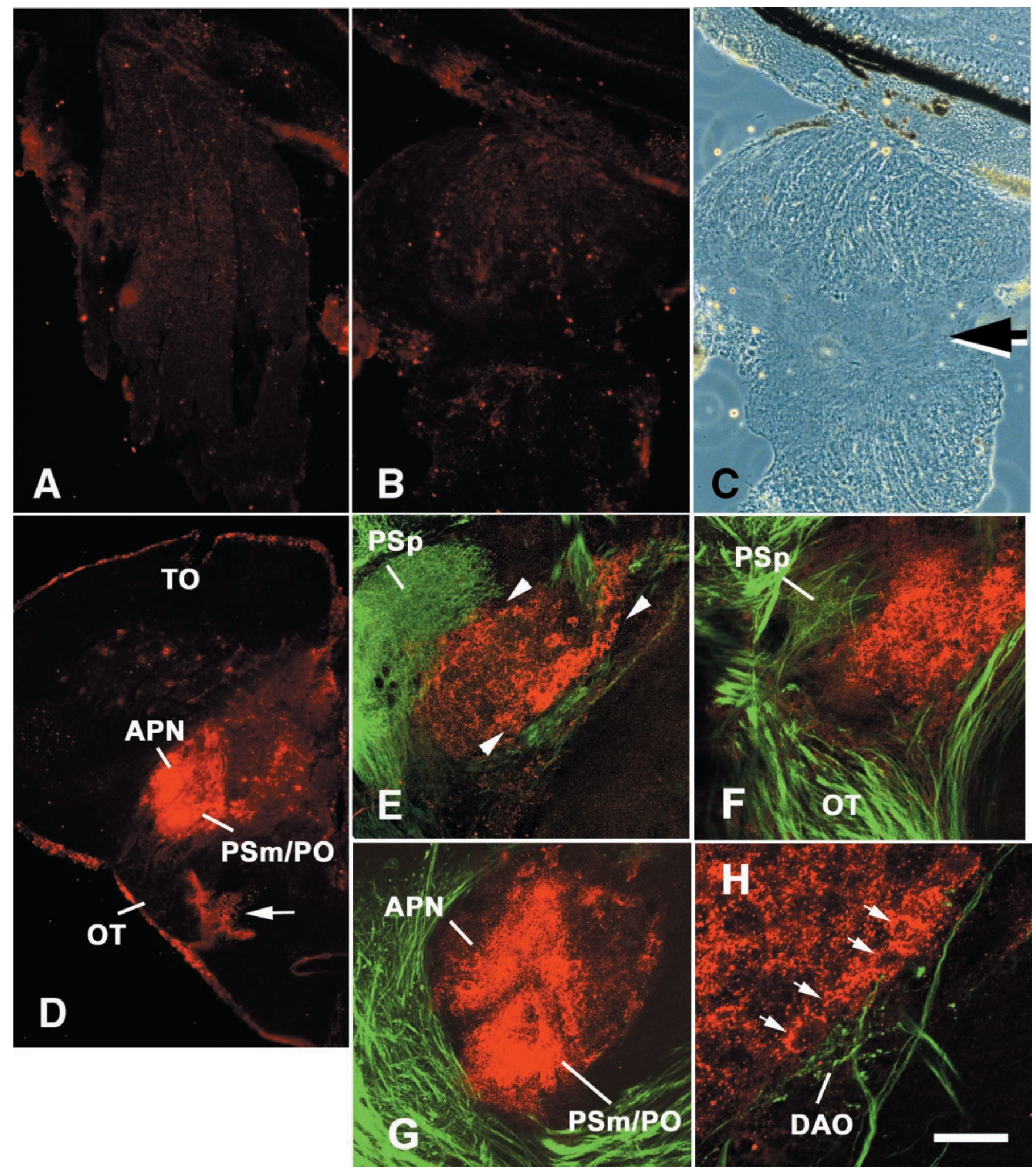

Figure 2. CS immunoreactivity is not increased after optic nerve crush but is constitutively present in specific pretectal brain nuclei. $A-C$, Longitudinal sections through the optic nerve are shown; the retina is at the top. CS immunoreactivity is low in the unlesioned optic nerve $(A)$ and is not altered $7 \mathrm{~d}$ after an optic nerve crush $(B)$. The crush site is indicated by an arrow in the phase-contrast image in $C$, corresponding to $B$. $D$, Cross section through a brain. Dorsal is at the top; lateral is left. CS immunoreactivity in an unlesioned animal is very low in the optic tract $(O T)$ and the tectum (TO) but intense in the magnocellular superficial/posterior pretectal nucleus $(P S m / P O)$ and the accessory pretectal nucleus $(A P N)$. The arrow points to CS-immunopositive meninges. $E-H$, Visualization of biocytin-labeled optic fibers ( green) and CS immunoreactivity (red) using confocal laser scanning microscopy. Orientations are the same as in $D$. E , The rostral magnocellular superficial pretectal nucleus (red) is contiguous with the parvocellular superficial pretectal nucleus $(P S p)$, which receives dense retinal fibers in an unlesioned animal. CS immunoreactivity is more intense at the border of the magnocellular superficial pretectal nucleus (arrowheads) than in its center. F, Three weeks after a lesion, CS immunoreactivity in the rostral (Figure legend continues.) 
$2.5 \mathrm{hr}$, and fish were killed by an overdose of aminobenzoic acid ethylmethylester $(0.1 \%$ for $5 \mathrm{~min})$ and perfused with $2 \%$ paraformaldehyde and $2 \%$ glutaraldehyde in PBS, $\mathrm{pH}$ 7.3. Perfused brains were sectioned at $50 \mu \mathrm{m}$ on a vibratome, and the signal was developed using the Vectastain ABC kit (Vector Laboratories, Burlingame, CA) with diaminobenzidine as substrate.

\section{Quantification of fibers invading the magnocellular superficial/posterior pretectal nucleus}

Invading fibers in the magnocellular superficial/posterior pretectal nucleus had circuitous trajectories and could not be counted individually. We determined the area taken by these fibers in cross sections of the magnocellular superficial and the posterior pretectal nuclei using the Neurolucida image analysis setup and software (MicroBrightField Europe, Magdeburg, Germany). Because we could not detect a clear anatomical border between the magnocellular superficial and the posterior pretectal nuclei, they were treated as one continuous area. All slides were coded so that the experimenter was blind to the treatment of the individual fish analyzed. The pretectal complex of brain nuclei that are immunopositive for CSs extends over 100-150 $\mu \mathrm{m}$ (i.e., two to three sections). The outlines of the parvocellular superficial, accessory, and magnocellular superficial/posterior pretectal nuclei (identified by the conspicuous cells at the borders of these nuclei) and the terminal fields in the dorsal accessory optic nucleus and in the central pretectal nucleus were marked under the microscope at a magnification of $400 \times$. The area covered by fibers invading the magnocellular superficial/posterior pretectal nucleus was also outlined. The magnocellular superficial/posterior pretectal nucleus was scored as being invaded by retinal ganglion cell axons when labeled axons were present in at least two consecutive sections. This is because fibers of the passing optic tract often obscured the magnocellular superficial/posterior pretectal nucleus in the most rostral section in which this nucleus was contained. Because the intensity of the label in the optic projection varied, only fish were analyzed in which the terminal fields in the dorsal accessory optic nucleus and the central pretectal nucleus, which border the magnocellular superficial/ posterior pretectal nucleus, were labeled. Brain nuclei were identified according to the method of Wullimann et al. (1996).

\section{RESULTS}

New fibers are continuously added to the optic projection in adult zebrafish because of sustained growth of the retina. These fibers terminate in the likewise growing optic tectum (the largest terminal field of optic axons) in a retinotopic manner. In the pretectum, the parvocellular superficial pretectal nucleus receives retinotopic innervation. Other terminal fields in the pretectal area are present in the central pretectal nucleus and in the dorsal accessory optic nucleus. Directly adjacent to these nuclei, there is a complex of pretectal nuclei embedded in the optic projection that does not receive retinal fibers and is intensely CSimmunopositive (Fig. 1). These nuclei are the magnocellular superficial pretectal nucleus, the posterior pretectal nucleus, and the accessory pretectal nucleus. The magnocellular superficial pretectal nucleus, which is situated medially to the caudal end of the parvocellular superficial pretectal nucleus, continues caudally into the posterior pretectal nucleus. (Because we were unable to find a clear anatomical separation for these two nuclei, they will be referred to as the magnocellular superficial/posterior pretectal nucleus in the analysis of invading fibers.) The accessory pretectal nucleus is situated directly lateral to the posterior pretectal nucleus (Wullimann et al., 1996).
After an optic nerve crush, the entire optic projection is restored. Fibers start to regrow by 1 week after the lesion, are frequently found on the tectum by 2 weeks after the lesion and, avoiding nonretinorecipient pretectal nuclei, have reinnervated all former targets by 4 weeks after the lesion (C. G. Becker et al., 2000).

\section{Selective presence of CSs in nonretinorecipient pretectal brain nuclei}

To analyze a possible role of CSs for normally growing optic fibers, regenerating optic fibers, or both, the distribution of CS immunoreactivity was analyzed in the optic pathway of unlesioned adult control animals and in animals that had received an optic nerve crush $7-21 \mathrm{~d}$ before analysis. In mice and salamanders, a lesion-induced increase of CS immunoreactivity in the optic nerve has been reported (Becker et al., 1995; SellesNavarro et al., 2001). However, in lesioned optic nerves of zebrafish, CS immunoreactivity was not increased at the crush site or caudal to it (Fig. $2 A-C$ ). In the retina (data not shown), optic nerve (Fig. $2 A-C$ ), chiasm (data not shown), optic tract (Fig. $2 D, F$ ), tectum (Fig. $2 D$ ), and other targets of optic axons, such as the parvocellular superficial pretectal nucleus (Fig. $2 E, F$ ) and the dorsal accessory optic nucleus (Fig. 2H), CS immunoreactivity was very low in unlesioned and lesioned animals. In contrast, nonretinorecipient pretectal nuclei, the accessory pretectal nucleus, the magnocellular superficial pretectal nucleus, and the posterior pretectal nucleus, were intensely labeled by CS antibodies in lesioned and unlesioned animals without detectable differences in fluorescence intensity between the lesioned and unlesioned situation (Fig. 2D-H). Large cells at the borders of these nuclei, which are probably neurons, appeared most strongly immunopositive (Fig. 2E,H). A lack of labeling after digestion of tissue sections with chondroitinase showed that the signal of antibody CS-56 was specific (data not shown).

The CS-expressing brain nuclei are embedded in the optic tract with terminal fields of optic fibers in the parvocellular superficial pretectal nucleus, in the central pretectal nucleus, and in the dorsal accessory optic nucleus surrounding them (Fig. 1). To further correlate the presence of CSs with the absence of optic fibers in nonretinorecipient nuclei, tracing of optic axons was combined with CS immunohistochemistry in unlesioned animals and those that had received an optic nerve crush 3 weeks before analysis. There was virtually no overlap between axon labeling and CS immunoreactivity at the border of the nonretinorecipient brain nuclei. In fact, nonlesioned and regenerating optic fibers grew in close association with the borders of these nuclei, but only very few of the axons crossed these borders (Fig. $2 E-H$ ).

Thus, a crush lesion of the optic nerve does not produce a possible CS barrier to axonal regeneration at the lesion site or in the optic pathway. The distribution of CS immunoreactivity and axons at the border of the nonretinorecipient pretectal nuclei, however, is consistent with the possibility that CSs provide a

\section{$\leftarrow$}

(Figure legend continued.) magnocellular superficial pretectal nucleus is comparable with that in unlesioned controls, and optic fibers have grown back through the optic tract $(O T)$ and reinnervate the parvocellular superficial pretectal nucleus $(P S p)$. $G$, In a more caudal cross section through the diencephalon, the accessory pretectal nucleus $(A P N)$ and the magnocellular superficial/posterior pretectal nucleus $(P S m / P O)$ are strongly labeled by CS antibodies 3 weeks after the lesion. Regenerating fibers grow around these nuclei. $H$, At a higher magnification, intensely CS-immunopositive cells (arrows) are detectable at the medial border of the magnocellular superficial/posterior pretectal nucleus in an animal 3 weeks after an optic nerve crush. Fibers with small protrusions, which are probably terminals in the dorsal accessory optic nucleus $(D A O)$ and smooth fibers, which are probably fibers of passage, grow along this boundary. Scale bar, $100 \mu \mathrm{m}$ (for $A-C$ ), $200 \mu \mathrm{m}$ (for $D$ ), $75 \mu \mathrm{m}$ (for $E-G$ ), $25 \mu \mathrm{m}$ (for $H$ ). 

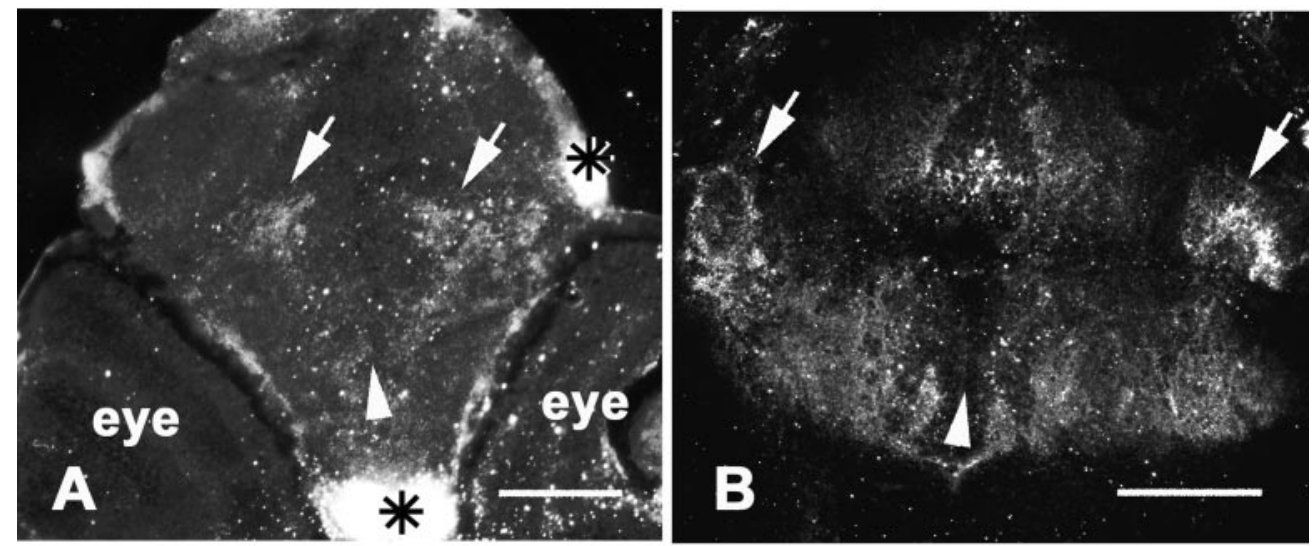

Figure 3. CS immunoreactivity is present in the pretectum during development. Cross sections through whole larvae are shown; dorsal is at the top; arrowheads in $A$ and $B$ indicate the brain midline; in $C$ and $D$, lateral is left. $A, C$, At $8 \mathrm{~d}$ of development, weak CS immunoreactivity is present in the pretectum (arrows). At higher magnification $(C)$, the characteristic small punctate appearance of CS labeling is visible $(C$, arrow). Large spots of immunoreactivity $(C$, arrowheads) are an artifact from material that separated from the intensely immunopositive cartilage $(A$, asterisks). Meninges are also CSimmunopositive (C, asterisks). $B, D$, By $28 \mathrm{~d}$ of development, immunoreactivity is distributed in a ring-like pattern in the lateral diencephalon (arrows), resembling the adult configuration. $D$ is a higher magnification of $B$. Cartilage ( $D$, asterisk) is intensely labeled. Scale bars: $A, B, 100 \mu \mathrm{m} ; C, D, 50 \mu \mathrm{m}$
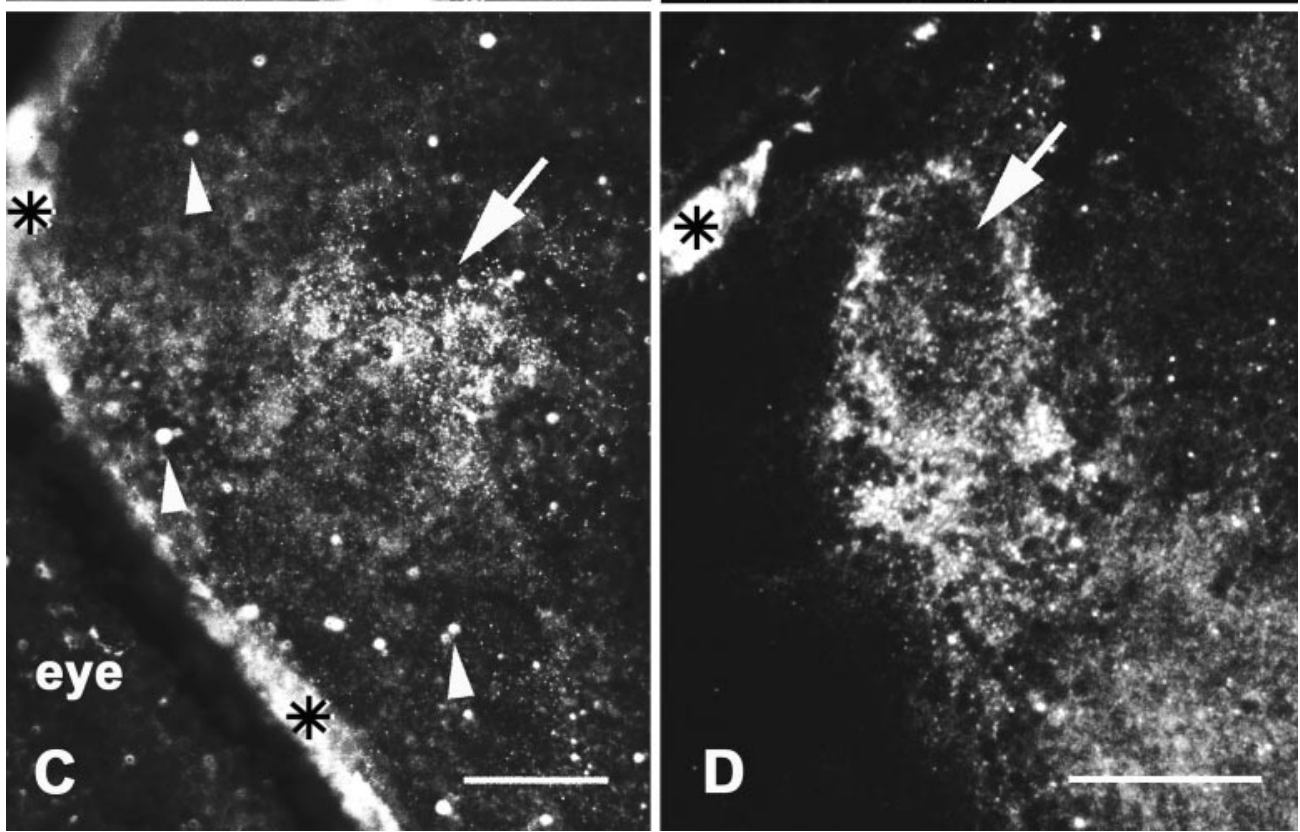

negative guidance signal for regenerating optic axons. This signal may also be read by growing axons of newly generated adult retinal ganglion cells in unlesioned animals.

\section{CS immunoreactivity in the developing diencephalon}

To analyze whether CSs in nonretinorecipient pretectal nuclei could also have a guidance function for the developing optic projection, we studied the developmental expression of CSs in the diencephalon. By $3 \mathrm{~d}$ of development, the first axons retinotopically innervate the tectum (Stuermer, 1988) and have established 10 distinct extratectal terminal fields, corresponding to those of the adult optic projection (Burrill and Easter, 1994). However, at $5 \mathrm{~d}$ of development, we failed to label CSs in the diencephalon (data not shown). Diffuse CS immunoreactivity was observed in the diencephalon by $8 \mathrm{~d}$ of development (Fig. 3A,C). By 4 weeks of development, when the brain is still rapidly growing, CS immunoreactivity was found in the developing pretectum, concentrated at the border of an ovoid nucleus (Fig. 3B,D). This pattern is similar in the adult. CS immunoreactivity was low in all other parts of the developing optic pathway. Thus, early optic axons ( $<8 \mathrm{~d}$ of development) may not be guided by CSs in the diencephalon, but at later stages of development, CSs could contribute to guidance of optic axons.

\section{Inhibition of regenerating adult retinal axons at a CS border in vitro}

To analyze whether regenerating adult optic axons of zebrafish are sensitive to a CS border and whether CSs are sufficient to repel these axons, they were confronted with a CS border in organotypic retinal culture (Fig. 4). For maximal axon outgrowth, adult fish received a conditioning bilateral optic nerve crush 1 week before explantation of retinal tissue. This treatment elicits outgrowth of retinal ganglion cell axons of mice (T. Becker et al., 2000), salamanders (Becker et al., 1999), and goldfish (Bastmeyer et al., 1991). Retinal explants were placed next to the border of a substrate spot of CSs. Laminin was present in these cultures within and around the spot area at a concentration that is sufficient to promote outgrowth of retinal axons. Neurites grew out of the explants by $24 \mathrm{hr}$. Judged by the rapid and polarized outgrowth of long fibers, similar to that of retinal ganglion cell axons of the closely related goldfish under the same culture conditions, it was concluded that these axons were most likely retinal ganglion cell axons of zebrafish. Interactions with the substrate border were analyzed by $3-4 \mathrm{~d}$ in vitro. For $77.8 \pm 9.25 \%$ (SEM) of the retinal explants ( $n=42$ explants), virtually all axonal fascicles showed a turning response at a substrate border of CSs and did not penetrate the substrate spot, despite the fact that 

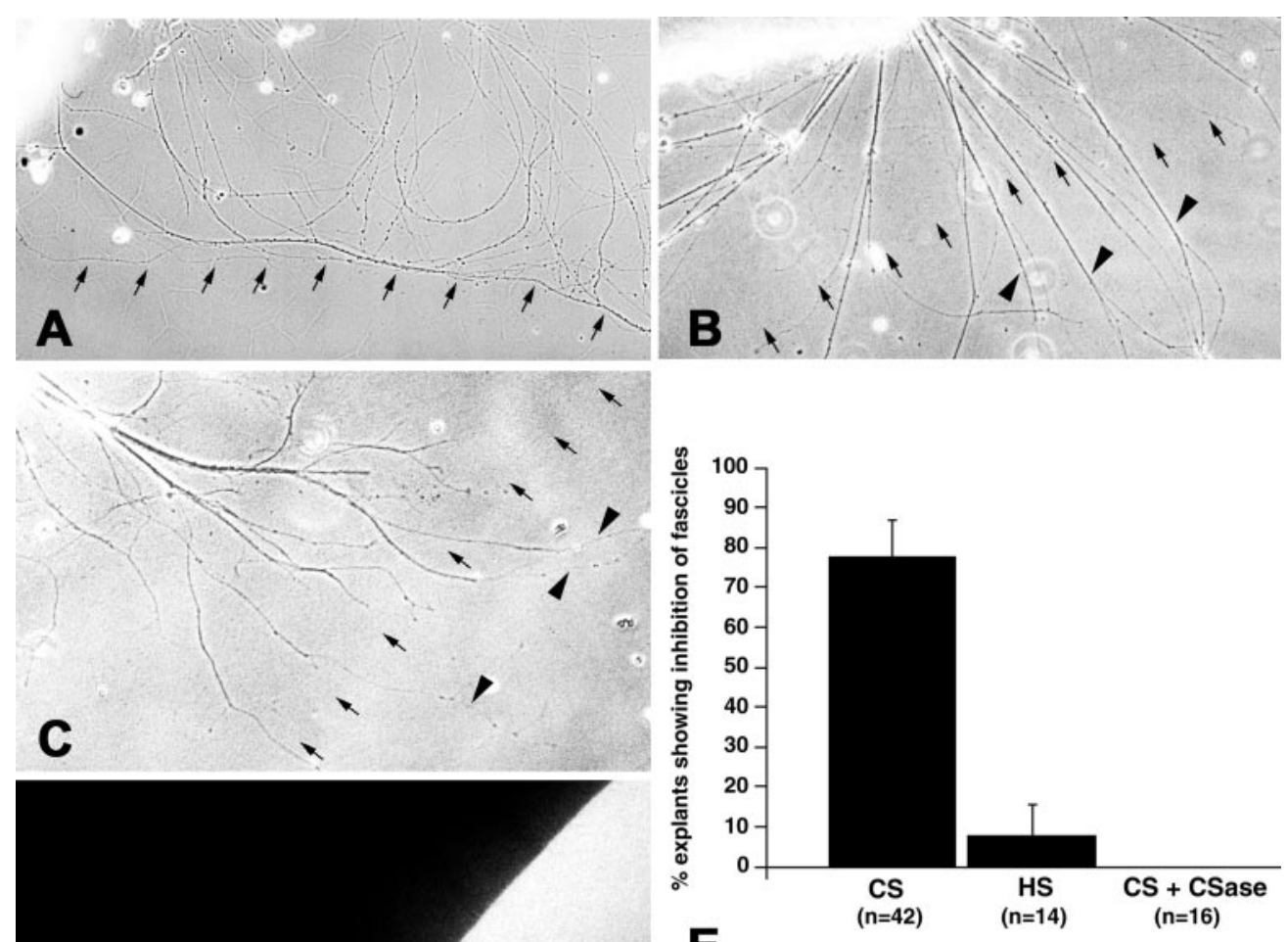

E

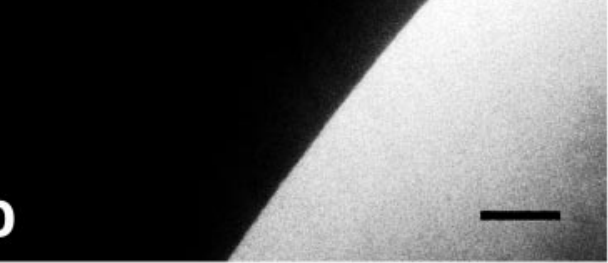

Figure 4. A substrate border of CSs but not HSs repels regenerating optic axons in vitro. $A-D$, Substrate borders of CSs $(A)$, HSs $(B)$, and CSs after chondroitinase treatment $(C)$ are indicated by small arrows. The position of the substrate border was visualized under fluorescence optics as shown in $D$, which is taken from the same area depicted in $C$. Fibers grow from retinal explants that are located in the top left corner. Although fibers are deflected at a CS border $(A)$, they readily invade a substrate spot of HSs $(B)$. The repellent activity of a CS border is abolished after treatment of the substrate with chondroitinase $(C)$. Arrowheads in $B$ and $C$ indicate fibers that crossed the substrate border. E, Quantification of the percentage of explants showing deflection of axons at a substrate border. Inhibition of axon growth at a CS border was statistically highly significant compared with HS borders or chondroitinase (CSase)-digested CS substrate spots (Fisher's exact test, $p \leq 0.0003 ; n=$ number of explants observed). Scale bar, $100 \mu \mathrm{m}$ (for $A-D$ ). laminin was present within the CS substrate spot (Fig. 4A,E). In contrast, spots of HSs, which are also highly charged sulfated glycosaminoglycans, were readily invaded by axonal fascicles. Only $7.7 \pm 7.70 \%$ of the explants $(n=14$ explants) were unable to grow axons onto an HS substrate spot (Fig. 4B,E). As an additional control, CS spots were digested with chondroitinase. This treatment abolished the border for axons of all explants analyzed ( $n=16$ explants; Fig. $4 C-E)$. Inhibition of axon growth at the CS border was statistically highly significant compared with HS border experiments (Fisher's exact test, $p=0.0003$ ) and chondroitinase-digested CS substrate spots (Fisher's exact test, $p<0.0001)$. Thus, CSs are sufficient to turn adult retinal axons of zebrafish away from a substrate border in vitro.

\section{Increased invasion of the magnocellular superficial/ posterior pretectal nucleus by regenerating optic fibers after chondroitinase injections in vivo}

To determine whether endogenous CSs contribute to negative guidance of regenerating optic axons in vivo, CSs were removed from the diencephalon during regeneration using chondroitinase. First, an effective protocol to remove CSs was developed, and then invasion of optic fibers into nonretinorecipient pretectal nuclei during regeneration was compared between chondroitinaseinjected and heparinase-injected, vehicle-injected, and uninjected control animals.

Chondroitinase was injected into the third ventricle of unlesioned animals, and the presence of CSs was analyzed 1 and $7 \mathrm{~d}$ after the injection. Although the enzyme was not targeted to the pretectum by this way of application, no general effects in the brain were expected, because CSs were highly localized to the pretectum. At $1 \mathrm{~d}$ after the injection $\mathrm{CS}$, immunoreactivity was completely abolished in the diencephalon (three animals; Fig. $5 A-C)$. At $7 \mathrm{~d}$ after the injection, CS immunoreactivity was present in the nonretinorecipient pretectal nuclei (three animals; Fig. $5 D$ ), albeit at a significantly lower labeling intensity than in uninjected brains (Fig. $5 A$ ), which were processed in parallel. Reappearing CS immunoreactivity was strongest around the somata of large neurons at the border of these pretectal nuclei (Fig. $5 D$ ). Successful removal of CSs from the brain was additionally controlled for by detecting neoepitopes (sugar stubs) created by chondroitinase injection in vivo with antibody $2 \mathrm{~B} 6$. The antibody did not show appreciable labeling in uninjected animals (Fig. 5E). At $1 \mathrm{~d}$ after chondroitinase injection, pretectal nuclei were labeled in a pattern highly similar to that labeled by the CS antibody CS-56 in uninjected animals (Fig. 5F). Radial glial cells in the brainstem that are immunopositive for CSs in uninjected animals were also labeled in chondroitinase-injected animals by antibody 2B6, indicating widespread diffusion of the enzyme. Thus, CSs were efficiently removed by chondroitinase, and injections had to be repeated every $7 \mathrm{~d}$ to remove newly expressed CSs.

To control whether another component of the extracellular matrix was also compromised by the enzyme treatment, immunohistochemistry for tenascin- $\mathrm{R}$ was performed in chondroitinase-injected animals. Tenascin- $\mathrm{R}$ is an inhibitory extracellular matrix protein that binds CSPGs (Xiao et al., 1997). The molecule is expressed in nonretinorecipient brain nuclei by probably the same large cells that are CS-immunopositive at the border of 
Figure 5. CS immunoreactivity but not tenascin-R immunoreactivity is removed from the magnocellular superficial pretectal nucleus of adult zebrafish in vivo by different enzymes. Cross sections are shown; dorsal is at the top; lateral is left. $A-D$, At $1 \mathrm{~d}$ after chondroitinase injection $(B)$, no CS immunoreactivity is detectable with antibody CS-56 in the magnocellular superficial pretectal nucleus compared with uninjected controls $(A)$. $C$, Phase-contrast image corresponding to $B$. $D$, At $7 \mathrm{~d}$ after injection, weak CS immunoreactivity is detectable with antibody CS-56 around large neurons in the magnocellular superficial pretectal nucleus (arrows). However, immunoreactivity is generally considerably lower than in uninjected controls $(A)$. $E, F$, At $1 \mathrm{~d}$ after chondroitinase injection $(F)$, chondroitin sulfate stub immunoreactivity, indicating successful removal of CSs, is increased in the magnocellular pretectal nucleus compared with uninjected controls $(E)$. $G, H$, Chondroitinase injection does not alter tenascin-R immunoreactivity 1 d after injection $(H)$ compared with uninjected controls $(G)$. $I, J$, CS immunoreactivity is reduced but still detectable in the magnocellular superficial pretectal nucleus $1 \mathrm{~d}$ after heparinase injection $(J)$ compared with uninjected controls that were processed on the same slide $(I)$. Scale bar, $100 \mu \mathrm{m}$.
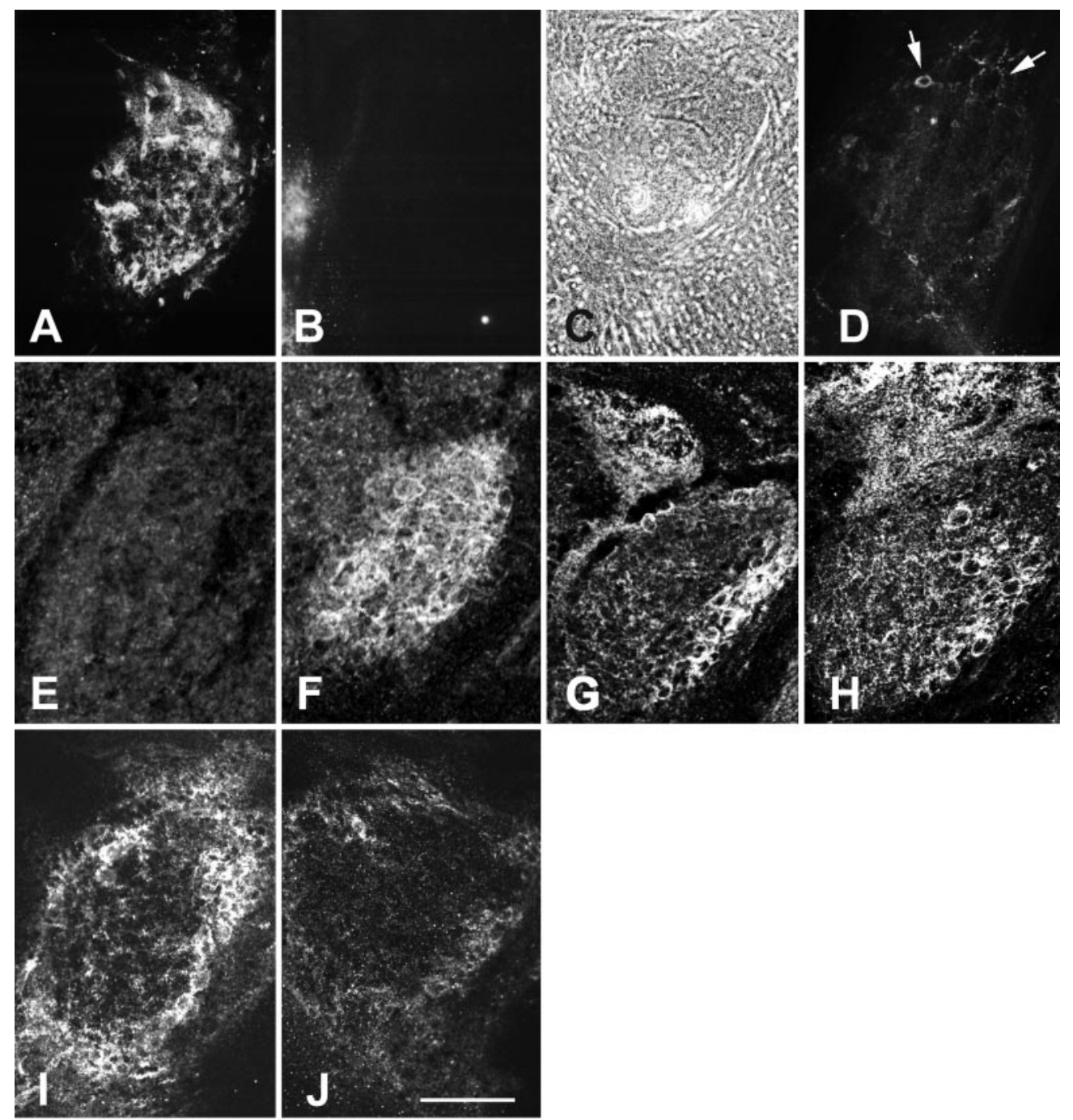

these nuclei, as shown by immunohistochemistry (Fig. 5G) and in situ hybridization (C. G. Becker, J. Schweitzer, T. Becker, and M. Schachner, unpublished observations). The distribution of tenascin-R immunoreactivity was not altered $1 \mathrm{~d}$ after chondroitinase treatment (Fig. 5H). CSs had been efficiently removed in these animals, as shown by the absence of CS labeling on alternating sections. This indicates that the enzyme treatment did not alter the distribution of another extracellular matrix molecule in nonretinorecipient pretectal brain nuclei.

Axons start to regrow by $\sim 1-2$ weeks after optic nerve crush, and retinotopic reinnervation of the tectum appeared complete by 4 weeks after the lesion (C. G. Becker et al., 2000). To minimize the number of repeated injections but still having a large number of regenerating axons at the level of the pretectum, optic nerves were crushed, and chondroitinase was injected 6 and $13 \mathrm{~d}$ after the lesion. Trajectories of regenerated axons were analyzed $24 \mathrm{~d}$ after the lesion if not indicated otherwise.

Because it is known that a number of axons commit errors in pathway selection (e.g., with respect to laterality at the chiasm and selection of optic nerve brachia during normal regeneration) (C. G. Becker et al., 2000), invasion of nonretinorecipient pretectal nuclei was analyzed in uninjected unlesioned (normal) animals and in uninjected animals that had received an optic nerve crush. In normal animals, the magnocellular superficial, accessory, and posterior pretectal nuclei were essentially free of optic fibers labeled by biocytin application to the optic nerve in all animals analyzed (zero of six animals had fibers in nonretinorecipient pretectal brain nuclei). In animals that had received an optic nerve crush without concomitant enzyme treatment, fibers grew abnormally into the magnocellular superficial/posterior pretectal nuclei in $47 \%$ of the animals analyzed ( 7 of 15 animals; see Fig. $7 C$ ). Thus, there is a proportion of animals showing erroneous growth of optic axons into the magnocellular superficial/posterior pretectal nucleus during normal regeneration, confirming previous findings in goldfish (Springer, 1981).

After injections of the BSA-containing vehicle solution during regeneration, $38 \%$ of the animals exhibited fibers in the magnocellular superficial/posterior pretectal nucleus (6 of 16 animals; Figs. $6 A, B, 7 B)$. This indicates that the injection of a protein solution during optic fiber regeneration did not increase the proportion of animals showing erroneous growth of optic axons into the magnocellular superficial/posterior pretectal nucleus.

In contrast, chondroitinase injections resulted in fiber invasion of the magnocellular superficial/posterior pretectal nucleus in $83 \%$ of the experimental animals (10 of 12 animals; Figs. 6C,D, $7 A$ ), which was significantly more (Fisher's exact test, $p=0.01$ ) than in the combined controls (uninjected and vehicle-injected). To obtain an indication of whether the invasion of the magnocel- 


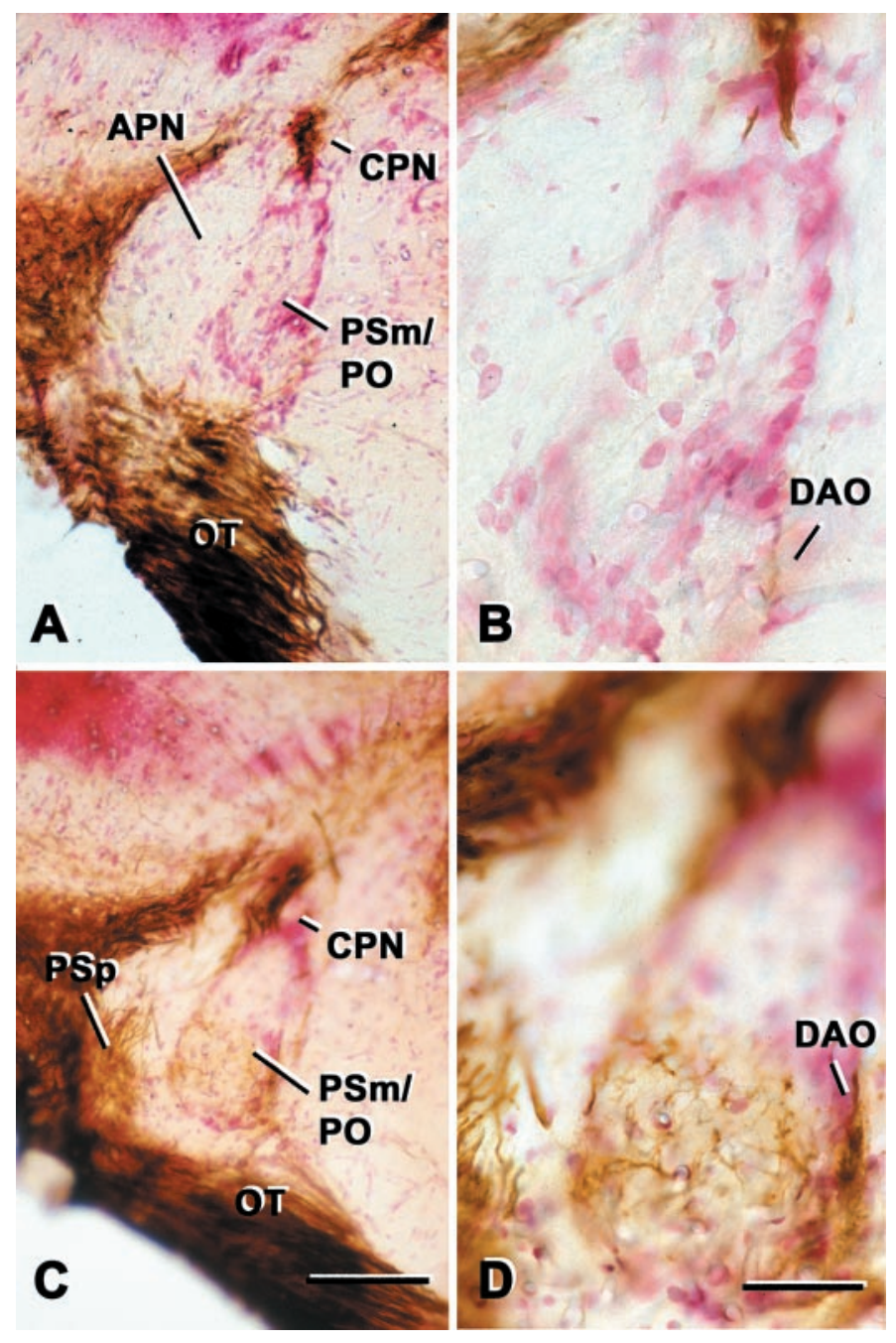

Figure 6. Retinal ganglion cell axons invade the magnocellular superficial/posterior pretectal nucleus after chondroitinase treatment. Vibratome cross sections ( $50 \mu \mathrm{m}$ in thickness) through the brain are shown. Optic fibers are labeled with biocytin in brown. Cell somata are counterstained with neutral red; dorsal is at the top; lateral is left. No fibers are detectable in the magnocellular superficial/posterior pretectal nucleus $(P S m / P O) 3$ weeks after a lesion of the contralateral optic nerve in a vehicle injected animal at low $(A)$ and high magnification $(B)$. In a chondroitinase-treated animal, fibers are present in the magnocellular superficial/posterior pretectal nucleus 3 weeks after a lesion of the contralateral optic nerve, depicted at low $(C)$ and high magnification $(D)$ of the same section. In the vehicle- and chondroitinase-injected cases, fibers are present in the central pretectal nucleus $(A, C, C P N)$ and the dorsal accessory optic nucleus $(B, D, D A O)$, which served as an internal control for efficient labeling of the optic projection. Note that the section in $C$ includes a part of the parvocellular superficial pretectal nucleus $(P S p)$, which is reinnervated by optic fibers, whereas the section depicted in $A$ is slightly more caudal and contains the accessory pretectal nucleus $(A P N)$ next to the magnocellular superficial/posterior pretectal nucleus ( $P S m /$ $P O$ ). Scale bars: $C, 100 \mu \mathrm{m}$ (for $A, C$ ); $\mathrm{D}, 40 \mu \mathrm{m}$ (for $B, D$ ).

lular superficial/posterior pretectal nucleus was transient in chondroitinase-injected animals, six animals received chondroitinase injections on days 6 and 13 after the lesion and were allowed to survive for $90 \mathrm{~d}$ after the optic nerve crush. Invasion of the magnocellular superficial/posterior pretectal nucleus was found in $83 \%$ of these fish (five of six animals), the same percentage as for animals analyzed $24 \mathrm{~d}$ after the crush (10 of 12). Hence, the erroneous invasion of the magnocellular superficial/posterior pre- tectal nucleus appears to persist for at least 3 months after a lesion of the optic nerve. Because CSs reappear $7 \mathrm{~d}$ after the last chondroitinase injection, which was on day 13 after the lesion, this finding suggests that reappearing CSs do not influence the fibers already present in the magnocellular superficial/posterior pretectal nucleus. Testing all chondroitinase-injected animals (shortand long-term survivors) against uninjected and vehicle-injected animals showed statistically highly significant differences in growth of fibers into the magnocellular superficial/posterior pretectal nucleus (Fisher's exact test, $p=0.003$ ).

As an additional control, animals were injected with another glycosaminoglycan-degrading enzyme, heparinase III, which releases HSs from the extracellular matrix. However, immunohistochemistry after heparinase injection revealed a diminished labeling intensity for CSs that was intermediate between that in uninjected controls and in chondroitinase injected animals at 1 (four animals) and 7 (two animals) d after the injection in all animals analyzed. Although CS immunoreactivity was completely abolished $1 \mathrm{~d}$ after chondroitinase injection, it was reduced to $\sim 60-80 \%$ of uninjected controls after heparinase injection (compare Fig. $5 A, B, I, J)$. The degree of reduction of CSs was estimated by measuring the relative fluorescence intensity in confocal sections of the pretectum (see Materials and Methods). This indicates that this heparinase preparation also contained a modest chondroitinase activity. After heparinase injections, 64\% ( 7 of 11; Fig. $7 D$ ) of the animals had fibers in the magnocellular superficial/posterior pretectal nucleus. This value was intermediate between those for chondroitinase-injected and control animals, correlated with the intermediate chondroitinase activity in this preparation. Thus, the small increase in the proportion of animals with fibers in the magnocellular superficial/posterior pretectal nucleus after heparinase III treatment $(\sim 22 \%$ compared with vehicle-injected and uninjected controls) probably reflects a specific dose effect of chondroitinase in the enzyme preparation. However, we cannot exclude that the effect could be attributable to digestion of HSs, because these may have functions similar to CSs (Garcia-Abreu et al., 2000). Heparinase treatment of sections from glial scar tissue has been found to augment axon growth on these sections in vitro but to a lesser extent than chondroitinase treatment (McKeon et al., 1995).

Interestingly, although the accessory pretectal nucleus was also efficiently freed of CS immunoreactivity by chondroitinase treatment, erroneous growth of fibers into this nucleus was rarely observed and was not different between enzyme-injected fish and controls. This suggests the presence of additional repellent molecules in this nucleus (see Discussion).

Although the proportion of animals exhibiting growth of fibers into the magnocellular superficial/posterior pretectal nucleus was significantly increased by chondroitinase injections, the density of fibers and the average cross-sectional area taken by invading fibers was not increased when control animals with fibers in the magnocellular superficial/posterior pretectal nucleus were compared with chondroitinase-injected cases (Fig. 7). This suggests that chondroitinase treatment increases the probability of axons crossing the intensely CS-positive border of the magnocellular superficial/posterior pretectal nucleus but does not influence growth of fibers once they have taken residence in the nucleus.

Erroneously growing fibers in the magnocellular superficial/ posterior pretectal nucleus appear to enter this nucleus from its ventrolateral margin, because they were present in this area in all animals in which the posterior pretectal nucleus was invaded (controls and chondroitinase-injected; Fig. 7). The reason why 
Figure 7. Outlines of the areas invaded by regenerating optic fibers in sections of the magnocellular superficial/posterior pretectal nucleus after different treatments. Chartings of all cases that received chondroitinase $(A)$, vehicle $(B)$, no injection $(C)$, or heparinase injection $(D)$ after contralateral optic nerve crush are shown; dorsal is at the top; lateral is left. The magnocellular superficial/posterior pretectal nucleus stretches over two to three cross sections. These are depicted in columns for the individual cases. All chartings are organized as in the first case in $B$, with the most rostral section on the bottom and the most caudal section on the top $(R \rightarrow C)$. The parvocellular superficial $(P S p)$, magnocellular superficial $(P S m)$, accessory $(A P N)$, central $(C P N)$, and posterior $(P O)$ pretectal nuclei, as well as the dorsal accessory optic nucleus $(D A O)$, are outlined as indicated for the first case in $B$. The area taken by fibers invading the magnocellular superfi$\mathrm{cial} /$ posterior pretectal nucleus in cross sections is black. Fibers reinnervating their regular terminal fields in the dorsal accessory optic nucleus and the central pretectal nucleus are gray. Fibers reinnervating the parvocellular superficial pretectal nucleus after a lesion have been omitted for clarity. Animals were scored as having fibers invading the magnocellular superficial/ posterior pretectal nucleus when fibers were present in these nuclei in at least
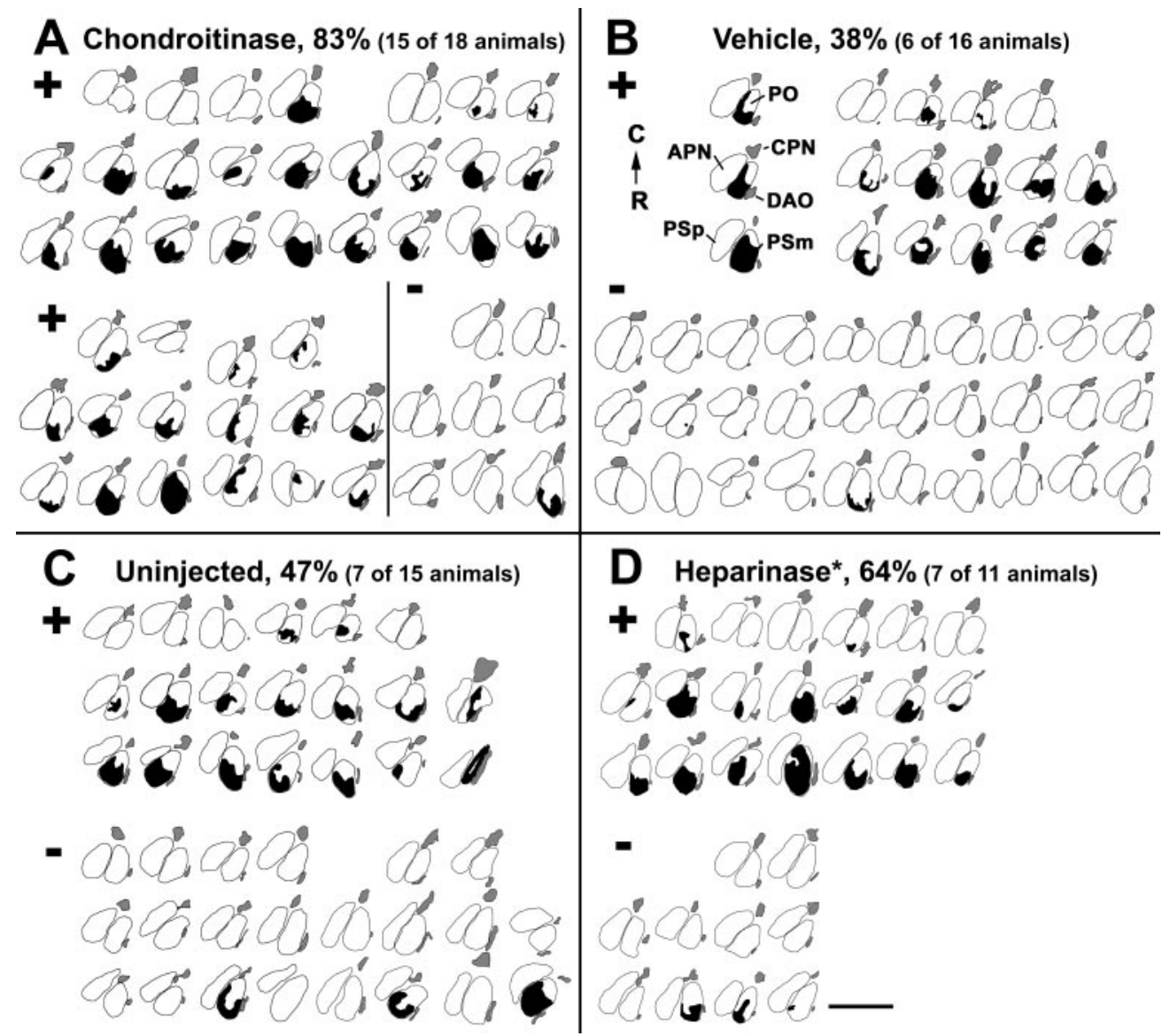

two consecutive sections (see Materials and Methods). Cases are sorted accordingly ( + , invasion of fibers; - , no invasion of fibers), and the percentages of cases with fibers in the magnocellular superficial/posterior pretectal nucleus are given. The proportion of cases with fibers in the magnocellular superficial/posterior pretectal nucleus after chondroitinase treatment is highly significantly increased $(p=0.003)$ compared with vehicle-injected and uninjected controls. *Note that the heparinase preparation contained chondroitinase activity (see Results). Scale bar, $200 \mu \mathrm{m}$.

fibers are prevented from invading the dorsal part of the magnocellular superficial/posterior pretectal nucleus or from overshooting their growth into the diencephalon remains unclear. Possible terminal arborization in the ventral part of the magnocellular superficial/posterior pretectal nucleus may be one reason why axons did not grow more deeply into the nucleus.

Alterations of trajectories of optic fibers attributable to chondroitinase treatment were expected only in the pretectum, because CSs were not present at conspicuous levels in other parts of the optic pathway. To exclude any nonspecific alterations of optic fibers, the optic pathway outside the pretectum was also examined in all experimental groups. In enzyme-injected and control animals with regenerating optic fibers, an increase in the number of ipsilateral fibers was noted, which is in agreement with previous observations (C. G. Becker et al., 2000). The shapes and sizes of terminal fields in thalamic targets of optic fibers and in the tectum were comparable with those in unlesioned animals in all experimental groups.

\section{DISCUSSION}

In this study we show that in the injured optic pathway of adult zebrafish, CS immunoreactivity is not increased to detectable levels by a lesion of the optic nerve. However, we provide in vivo and in vitro evidence that constitutively present CSs at the border of nonretinorecipient brain nuclei form a barrier for optic axons during regeneration and thus provide negative guidance information during target selection of these axons.

We observed increased growth of fibers into the magnocellular superficial/posterior pretectal nucleus after chondroitinase treatment in vivo, which was probably a specific consequence of the removal of CSs rather than of a general destabilization of the extracellular matrix. Immunoreactivity for another component of the extracellular matrix, tenascin-R (Pesheva et al., 1989), was unchanged in the nonretinorecipient pretectal brain nuclei, although tenascin-R binds at least one CSPG, namely phosphacan (Xiao et al., 1997), and may by itself carry CS side chains (Probstmeier et al., 2000a,b). Moreover, the percentage of animals with fibers in the magnocellular superficial/posterior pretectal nucleus after treatment with a heparinase $(64 \%)$ preparation that contained a low chondroitinase activity (see Results) was intermediate between those of control $(41 \%)$ and chondroitinasetreated $(83 \%)$ animals, suggesting a dose-dependent effect of CSs on optic axons at the border of the magnocellular superficial/ posterior pretectal nucleus.

Although chondroitinase treatment significantly increased the number of animals with fibers invading the magnocellular superficial/posterior pretectal nucleus, a substantial proportion of uninjected and vehicle-injected animals (41\%), in which the distribution of CS was uncompromised, also showed growth of optic fibers into this nucleus. One possible explanation for this is that, 
unlike newly generated axons in unlesioned animals, regenerating axons grow as a front, i.e., a large number of growth cones encounter nonretinorecipient pretectal nuclei simultaneously in the absence of preexisting fibers, which could be a substrate for axonal fasciculation along the correct pathway. Thus, with a disturbed balance between attractive and repellent cues, a fraction of the axons may commit navigational errors in a stochastic manner. Pathway errors may be amplified by fasciculation of axons along erroneous pathways. Pathway errors committed by regenerating optic axons in fish are well known phenomena (Springer, 1981; C. G. Becker et al., 2000).

Regenerating optic axons of zebrafish are probably repelled by CSs directly, as suggested by the fact that a CS substrate spot in vitro induces neurites (which most likely are regenerating retinal ganglion cell axons) from adult retinal explants to grow around its border. This finding is in agreement with data showing that developing optic axons (Snow et al., 1991; Brittis et al., 1992; Snow and Letourneau, 1992) as well as other developing axons (Dou and Levine, 1995) of mammals are repelled by a border of CSs in vitro. In contrast, specific CS epitopes promote neurite outgrowth (Faissner et al., 1994; Clement et al., 1998). Soluble CSs promote the growth of optic axons of goldfish (Challacombe and Elam, 1997). This underscores that the axonal reaction to CSs (Snow and Letourneau, 1992; Snow et al., 1996; Hynds and Snow, 1999) and also to other matrix molecules, such as tenascins (Lochter et al., 1991, 1994; Lochter and Schachner, 1993; Pesheva et al., 1993; Taylor et al., 1993), depends on the way the molecules are presented to the axons (as a homogeneous or step gradient substrate or soluble in the culture medium). The complex reactions of developing optic axons in slice cultures of the optic chiasm of mice (Chung et al., 2000) to the removal of CSs may be related to the potential role of the spatial configuration in which the molecules are encountered in a specific CNS structure. There is also evidence to suggest that CSs are anchor points for guidance molecules (Emerling and Lander, 1994, 1996).

CSs are not the only axon-repellent molecules in the pretectum. The accessory pretectal nucleus, which is normally also strongly CS-immunoreactive, did not show appreciable invasion of fibers after removal of CSs. Moreover, erroneously growing fibers in the magnocellular superficial/posterior pretectal nucleus after CS removal were not as dense as in adjacent "appropriate" terminal fields of retinorecipient nuclei. Reappearing CSs may prevent late-coming axons from invading nonretinorecipient pretectal nuclei. However, there are additional molecules that could contribute to the inhibition of axon growth through the border of nonretinorecipient pretectal nuclei and could in part substitute for the function of CSs after chondroitinase treatment. One of these molecules may be tenascin-R, because it also repels optic axons of chicks (Taylor et al., 1993), salamanders (Becker et al., 1999), and mice (T. Becker et al., 2000). In fact, tenascin-R immunoreactivity is stronger in the accessory pretectal nucleus than in the magnocellular superficial/posterior pretectal nucleus, which correlates with the absence of invading fibers in the accessory pretectal nucleus after chondroitinase treatment (data not shown). In addition, two axon-repellent semaphorins, sema Z1a (Shoji et al., 1998) and sema Z1b (Roos et al., 1999), are strongly expressed in the large neurons at the medial border of the magnocellular superficial/posterior pretectal nucleus (D. Gimnopoulos, T. Becker, C. G. Becker, and M. Schachner, unpublished observations).

Repellent or inhibitory guidance by CSs may be important for regenerating as well as developing axons. In teleosts, the magno- cellular superficial pretectal nucleus receives secondary visual input from the tectum (Yoshimoto and Ito, 1993), and the separation of primary and secondary visual information is conceivably of functional significance for the visual system. We could not detect CSs in the optic pathway at $5 \mathrm{~d}$ of development, when the initial projections of optic fibers to extratectal targets (Burrill and Easter, 1994) and the tectum (Stuermer, 1988) are already in place. Shortly after that ( $8 \mathrm{~d}$ of development), however, diff use CS immunoreactivity was detectable in the pretectum. By 4 weeks of development, when the brain is still growing rapidly, CS immunoreactivity resembles the adult pattern. This suggests that pioneering fibers of the optic projection may not be guided by CSs, but that with increasing complexity of the differentiating brain, this cue becomes important for the developing optic projection. The optic projection of fish grows throughout life (Meyer, 1978; Marcus et al., 1999), correlated with the constitutive expression of positive (netrin-1; Petrausch et al., 2000) and negative (ephrin-A2 and -A5; C. G. Becker et al., 2000) guidance cues in the adult that are developmentally downregulated in mammals (Wizenmann et al., 1993).

In zebrafish spontaneous axonal regeneration beyond a CNS lesion site may in part be attributable to the absence of CSs, which in mammals are increased in expression at the lesion site. We did not find a lesion-induced increase in CS immunoreactivity in the optic nerve of zebrafish, whereas in the optic nerve (Selles-Navarro et al., 2001) and spinal cord of mammals (Davies et al., 1997, 1999; Pasterkamp et al., 2001), detectability of CSs and their core proteins (Levine, 1994; McKeon et al., 1999) is strongly increased after a lesion. However, increased expression of CSs in the injured optic nerve of the goldfish, which is closely related to zebrafish, has been described previously (Battisti et al., 1992). In the investigation on goldfish, other antibodies to CSs have been used than in our present analysis, and it is possible that the epitope recognized by the CS-56 antibody (Avnur and Geiger, 1984; Sorrell et al., 1993) is not present in all CS-expressing structures. Nevertheless, it has been shown that the CS epitope structure recognized by CS-56 closely correlates with inhibition of axon growth on glial cells in vitro (Fidler et al., 1999; Niederöst et al., 1999) and in glial scars in vivo (Davies et al., 1997, 1999; Moon et al., 2001; Plant et al., 2001). Microtransplanted neurons that grow in the spinal white matter of rats stop growing when they encounter a CS-immunopositive lesion site (Davies et al., 1999). Recently, it has been shown that the removal of CSs at the lesion site in vivo induces regrowth of injured nigrostriatal fibers in rats (Moon et al., 2001).

Similar to CSs, some other inhibitory molecules thought to be responsible for the lack of axonal regeneration in adult mammals may be absent or removed from the spontaneously regenerating CNS of anamniotes. In vitro evidence suggests that the myelin inhibitor Nogo-1 (Chen et al., 2000) is absent (Lang et al., 1995; Wanner et al., 1995) or expressed at lower levels (Sivron et al., 1994) in the regenerating CNS of fish and amphibians. Tenascin-R, another oligodendrocyte-derived inhibitor of axon growth (Pesheva et al., 1989), persists after optic nerve crush in mice (T. Becker et al., 2000) but disappears from the injured nerve of salamanders concomitantly with regeneration of optic fibers (Becker et al., 1999).

In conclusion, the absence of growth-inhibitory molecules from lesioned pathways may contribute to spontaneous axonal regeneration after injury in the CNS of anamniotes. In the present study, this correlation is exemplified by the absence of CSs from a crush site of the optic nerve of zebrafish. However, inhibitory or 
repellent molecules may be very important for correct guidance, as shown by the repellent environment encountered by optic axons at the border of CS-expressing nonretinorecipient pretectal brain nuclei. Extrapolated to the situation in mammals, our results suggest that neutralization of inhibitory molecules along axonal pathways is one way to facilitate axon regrowth. However, inhibitory signals may be necessary at sites of pathway choices and in target areas of regenerating axons to accomplish correct guidance.

\section{REFERENCES}

Anderson RB, Walz A, Holt CE, Key B (1998) Chondroitin sulfates modulate axon guidance in embryonic Xenopus brain. Dev Biol 202:235-243.

Avnur Z, Geiger B (1984) Immunocytochemical localization of native chondroitin-sulfate in tissues and cultured cells using specific monoclonal antibodies. Cell 38:811-822.

Bastmeyer M, Beckmann M, Schwab ME, Stuermer CAO (1991) Growth of regenerating goldfish axons is inhibited by rat oligodendrocytes and CNS myelin but not by goldfish optic nerve tract oligodendrocyte-like cells and fish CNS myelin. J Neurosci 11:626-640.

Battisti WP, Shinar Y, Schwartz M, Levitt P, Murray M (1992) Temporal and spatial patterns of expression of laminin, chondroitin sulphate proteoglycan and HNK-1 immunoreactivity during regeneration in the goldfish optic nerve. J Neurocytol 21:557-573.

Becker CG, Becker T, Meyer RL, Schachner M (1999) Tenascin-R inhibits the growth of optic fibers in vitro but is rapidly eliminated during optic nerve regeneration in the salamander Pleurodeles waltl. J Neurosci 19:813-827.

Becker CG, Meyer RL, Becker T (2000) Gradients of ephrin-A2 and ephrin-A5b mRNA during retinotopic regeneration of the optic projection in adult zebrafish. J Comp Neurol 427:469-483.

Becker T, Becker CG, Niemann U, Naujoks-Manteuffel C, Bartsch U, Schachner M, Roth G (1995) Immunohistological localization of tenascin-C in the developing and regenerating retinotectal system of two amphibian species. J Comp Neurol 360:643-657.

Becker T, Anliker B, Becker CG, Taylor J, Schachner M, Meyer RL, Bartsch U (2000) Tenascin-R inhibits regrowth of optic fibers in vitro, persists in the optic nerve of mice after injury Glia 29:330-346.

Bernhardt RR (1999) Cellular and molecular bases of axonal regeneration in the fish central nervous system. Exp Neurol 157:223-240.

Bernhardt RR, Schachner M (2000) Chondroitin sulfates affect the formation of the segmental motor nerves in zebrafish embryos. Dev Biol 221:206-219.

Bicknese AR, Sheppard AM, O'Leary DDM, Pearlman AL (1994) Thalamocortical axons extend along a chondroitin sulfate proteoglycan-enriched pathway coincident with the neocortical subplate and distinct from the efferent path. J Neurosci 14:3500-3510.

Bovolenta P, Fernaud-Espinosa I (2000) Nervous system proteoglycans as modulators of neurite outgrowth. Prog Neurobiol 61:113-132.

Braunewell KH, Martini R, Lebaron R, Kresse H, Faissner A, Schmitz B, Schachner M (1995) Up-regulation of a chondroitin sulphate epitope during regeneration of mouse sciatic nerve. Evidence that the immunoreactive molecules are related to the chondroitin sulphate proteoglycans decorin and versican. Eur J Neurosci 7:792-804.

Brittis PA, Canning DR, Silver J (1992) Chondroitin sulfate as a regulator of neuronal patterning in the retina. Science 255:733-736.

Burrill JD, Easter SS (1994) Development of the retinof ugal projections in the embryonic and larval zebrafish (Brachydanio rerio). J Comp Neurol 346:583-600.

Challacombe JF, Elam JS (1997) Chondroitin 4-sulfate stimulates regeneration of goldfish retinal axons. Exp Neurol 143:10-17.

Chen MS, Huber AB, van der Haar ME, Frank M, Schnell L, Spillmann AA, Christ F, Schwab ME (2000) Nogo-A is a myelin-associated neurite outgrowth inhibitor, an antigen for monoclonal antibody IN-1 Nature 403:434-439.

Chung KY, Taylor JS, Shum DK, Chan SO (2000) Axon routing at the optic chiasm after enzymatic removal of chondroitin sulfate in mouse embryos. Development 127:2673-2683.

Clement AM, Nadanaka S, Masayama K, Mandl C, Sugahara K, Faissner A (1998) The DSD-1 carbohydrate epitope depends on sulfation, correlates with chondroitin sulfate D motifs, and is sufficient to promote neurite outgrowth. J Biol Chem 273:28444-28453.

Davies SJ, Goucher DR, Doller C, Silver J (1999) Robust regeneration of adult sensory axons in degenerating white matter of the adult rat spinal cord. J Neurosci 19:5810-5822.

Davies SJA, Fitch MT, Memberg SP, Hall AK, Raisman G, Silver J (1997) Regeneration of adult axons in white matter tracts of the central nervous system. Nature 390:680-683.

Dou CL, Levine JM (1994) Inhibition of neurite growth by the NG2 chondroitin sulfate proteoglycan. J Neurosci 14:7616-7628.
Dou CL, Levine JM (1995) Differential effects of glycosaminoglycans on neurite growth on laminin and L1 substrates. J Neurosci 15:8053-8066.

Emerling DE, Lander AD (1994) Laminar specific attachment and neurite outgrowth of thalamic neurons on cultured slices of developing cerebral neocortex. Development 120:2811-2822.

Emerling DE, Lander AD (1996) Inhibitors and promoters of thalamic neuron adhesion and outgrowth in embryonic neocortex: functional association with chondroitin sulfate. Neuron 17:1089-1100.

Faissner A, Steindler D (1995) Boundaries and inhibitory molecules in developing neural tissues. Glia 13:233-254.

Faissner A, Clement A, Lochter A, Streit A, Mandl C, Schachner M (1994) Isolation of a neural chondroitin sulfate proteoglycan with neurite outgrowth promoting properties. J Cell Biol 126:783-799.

Fawcett JW, Asher RA (1999) The glial scar and central nervous system repair. Brain Res Bull 49:377-391.

Fawcett JW, Geller HM (1998) Regeneration in the CNS: optimism mounts. Trends Neurosci 21:179-180.

Fernaud-Espinosa I, Nieto-Sampedro M, Bovolenta P (1994) Differential effects of glycosaminoglycans on neurite outgrowth from hippocampal and thalamic neurones. J Cell Sci 107:1437-1448.

Fernaud-Espinosa I, Nieto-Sampedro M, Bovolenta P (1996) Developmental distribution of glycosaminoglycans in embryonic rat brain: relationship to axonal tract formation. J Neurobiol 30:410-424.

Fidler PS, Schuette K, Asher RA, Dobbertin A, Thornton SR, CallePatino Y, Muir E, Levine JM, Geller HM, Rogers JH, Faissner A, Fawcett JW (1999) Comparing astrocytic cell lines that are inhibitory or permissive for axon growth: The major axon-inhibitory proteoglycan is NG2. J Neurosci 19:8778-8788.

Garcia-Abreu J, Mendes FA, Onofre GR, De Freitas MS, Silva LC, Moura Neto V, Cavalcante LA (2000) Contribution of heparan sulfate to the non-permissive role of the midline glia to the growth of midbrain neurites. Glia 29:260-272.

Garwood J, Schnadelbach O, Clement A, Schütte K, Bach A, Faissner A (1999) DSD-1-proteoglycan is the mouse homolog of phosphacan and displays opposing effects on neurite outgrowth dependent on neuronal lineage. J Neurosci 19:3888-3899.

Hynds DL, Snow DM (1999) Neurite outgrowth inhibition by chondroitin sulfate proteoglycan: stalling/stopping exceeds turning in human neuroblastoma growth cones. Exp Neurol 160:244-255.

Lagenaur C, Lemmon V (1987). An L1-like molecule, the 8D9 antigen, is a potent substrate for neurite extension. Proc Natl Acd Sci USA 84:7753-7757.

Lang DM, Rubin BP, Schwab ME, Stuermer CAO (1995) CNS myelin and oligodendrocytes of the Xenopus spinal cord-but not optic nerve-are nonpermissive for axon growth. J Neurosci 15:99-109.

Levine JM (1994) Increased expression of the NG2 chondroitin-sulfate proteoglycan after brain injury. J Neurosci 14:4716-4730.

Lochter A. Schachner M (1993) Tenascin and extracellular matrix glycoproteins-from promotion to polarization of neurite growth in vitro. J Neurosci 13:3986-4000.

Lochter A, Vaughan L, Kaplony A, Prochiantz A, Schachner M, Faissner A (1991) J1/tenascin in substrate-bound and soluble form displays contrary effects on neurite outgrowth. J Cell Biol 113:1159-1171.

Lochter A, Taylor J, Fuss B, Schachner M (1994) The extracellular matrix molecule janusin regulates neuronal morphology in a substrateand culture time-dependent manner. Eur J Neurosci 6:597-606.

Marcus RC, Delaney CL, Easter Jr SS (1999) Neurogenesis in the visual system of embryonic and adult zebrafish (Danio rerio). Vis Neurosci 16:417-424.

Martin GF, Ghooray GT, Wang XM, Xu XM, Zou XC (1994) Models of spinal cord regeneration. In: Progress in brain research: neural regeneration (Seil FJ, ed), pp 175-201. Amsterdam: Elsevier.

McKeon RJ, Hoke A, Silver J (1995) Injury-induced proteoglycans inhibit the potential for laminin-mediated axon growth on astrocytic scars. Exp Neurol 136:32-43.

McKeon RJ, Jurynec MJ, Buck CR (1999) The chondroitin sulfate proteoglycans neurocan and phosphacan are expressed by reactive astrocytes in the chronic CNS glial scar. J Neurosci 19:10778-10788.

Meyer RL (1978) Evidence from thymidine labeling for continuing growth of retina and tectum in juvenile goldfish. Exp Neurol 59:99-111.

Moon LD, Asher RA, Rhodes KE, Fawcett JW (2001) Regeneration of CNS axons back to their target following treatment of adult rat brain with chondroitinase ABC. Nat Neurosci 4:465-466.

Nadanaka S, Clement A, Masayama K, Faissner A, Sugahara K (1998) Characteristic hexasaccharide sequences in octasaccharides derived from shark cartilage chondroitin sulfate D with a neurite outgrowth promoting activity. J Biol Chem 273:3296-3307.

Niederöst BP, Zimmermann DR, Schwab ME, Bandtlow CE (1999) Bovine CNS myelin contains neurite growth-inhibitory activity associated with chondroitin sulfate proteoglycans. J Neurosci 19:8979-8989.

Oakley RA, Tosney KW (1991) Peanut agglutinin and chondroitin-6sulfate are molecular markers for tissues that act as barriers to axon advance in the avian embryo. Dev Biol 147:187-206.

Pasterkamp RJ, Anderson PN, Verhaagen J (2001) Peripheral nerve injury fails to induce growth of lesioned ascending dorsal column axons 
into spinal cord scar tissue expressing the axon repellent Semaphorin3A. Eur J Neurosci 13:457-471.

Pesheva P, Spiess E, Schachner M (1989) J1-160 and J1-180 are oligodendrocyte-secreted nonpermissive substrates for cell adhesion. J Cell Biol 109:1765-1778.

Pesheva P, Gennarini G, Goridis C, Schachner M (1993) The F3/11 cell adhesion molecule mediates the repulsion of neurons by the extracellular matrix glycoprotein J1-160/180. Neuron 10:69-82.

Petrausch B, Jung M, Leppert CA, Stuermer CA (2000) Lesion-induced regulation of netrin receptors and modification of netrin-1 expression in the retina of fish and grafted rats. Mol Cell Neurosci 16:350-364.

Plant GW, Bates ML, Bunge MB (2001) Inhibitory proteoglycan immunoreactivity is higher at the caudal than the rostral Schwann cell graft-transected spinal cord interface. Mol Cell Neurosci 17:471-487.

Probstmeier R, Braunewell K, Pesheva P (2000a) Involvement of chondroitin sulfates on brain-derived tenascin- $\mathrm{R}$ in carbohydrate-dependent interactions with fibronectin and tenascin-C. Brain Res 863:42-51.

Probstmeier R, Stichel CC, Müller HW, Asou H, Pesheva P (2000b) Chondroitin sulfates expressed on oligodendrocyte-derived tenascin-R are involved in neural cell recognition. Functional implications during CNS development and regeneration. J Neurosci Res 60:21-36.

Qiu J, Cai D, Filbin MT (2000) Glial inhibition of nerve regeneration in the mature mammalian CNS. Glia 29:166-174.

Roos M, Schachner M, Bernhardt RR (1999) Zebrafish semaphorin Z1b inhibits growing motor axons in vivo. Mech Dev 87:103-117.

Selles-Navarro I, Ellezam B, Fajardo R, Latour M, McKerracher L (2001) Retinal ganglion cell and nonneuronal cell responses to a microcrush lesion of adult rat optic nerve. Exp Neurol 167:282-289.

Shoji W, Yee CS, Kuwada JY (1998) Zebrafish semaphorin Z1a collapses specific growth cones and alters their pathway in vivo. Development 125:1275-1283.

Silver J (1994) Inhibitory molecules in development and regeneration. J Neurol 242:S22-24.

Sivron T, Schwab ME, Schwartz M (1994) Presence of growth inhibitors in fish optic nerve myelin-postinjury changes. J Comp Neurol 343:237-246.

Snow DM, Letourneau PC (1992) Neurite outgrowth on a step gradient of chondroitin sulfate proteoglycan (CS-PG). J Neurobiol 23:322-336.

Snow DM, Lemmon V, Carrino DA, Silver J (1990) Sulphated proteoglycans present in astroglial barriers during development in vivo inhibit neurite outgrowth in vitro. Exp Neurol 109:111-130.

Snow DM, Watanabe M, Letourneau PC, Silver J (1991) A chondroitin sulfate proteoglycan may influence the direction of retinal ganglion cell outgrowth. Development 113:1473-1485.

Snow DM, Brown EM, Letourneau PC (1996) Growth cone behavior in the presence of soluble chondroitin sulfate proteoglycan (CSPG), compared to behavior on CSPG bound to laminin or fibronectin. Int J Dev Neurosci 14:331-349.

Sorrell JM, Carrino DA, Caplan AI (1993) Structural domains in chondroitin sulfate identified by anti-chondroitin sulfate monoclonal antibodies. Immunosequencing of chondroitin sulfates. Matrix 13:351-361.

Springer AD (1981) Normal and abnormal retinal projections following the crush of one optic nerve in goldfish (Carassius auratus). J Comp Neurol 199:87-95.

Stuermer CA (1988) Retinotopic organization of the developing retinotectal projection in the zebrafish embryo. J Neurosci 8:4513-4530.

Taylor J, Pesheva P, Schachner M (1993) Influence of janusin and tenascin on growth cone behavior in vitro. J Neurosci Res 35:347-362.

Wanner M, Lang DM, Bandtlow CE, Schwab ME, Bastmeyer M, Stuermer CAO (1995) Reevaluation of the growth-permissive substrate properties of goldfish optic nerve myelin and myelin proteins. J Neurosci 15:7500-7508.

Wilson MT, Snow DM (2000) Chondroitin sulfate proteoglycan expression pattern in hippocampal development: potential regulation of axon tract formation. J Comp Neurol 424:532-546.

Wizenmann A, Thies E, Klostermann S, Bonhoeffer F, Bähr M (1993) Appearance of target-specific guidance information for regenerating axons after CNS lesions. Neuron 11:975-983.

Wullimann MF, Rupp B, Reichert H (1996) Neuroanatomy of the zebrafish brain: a topological atlas. Basel: Birkhäuser.

Xiao ZC, Bartsch U, Margolis RK, Rougon G, Montag D, Schachner M (1997) Isolation of a tenascin-R binding protein from mouse brain membranes. A phosphacan-related chondroitin sulfate proteoglycan. J Biol Chem 272:32092-32101.

Yick LW, Wu W, So KF, Yip HK, Shum DK (2000) Chondroitinase ABC promotes axonal regeneration of Clarke's neurons after spinal cord injury NeuroReport 11:1063-1067.

Yoshimoto M, Ito H (1993) Cytoarchitecture, fiber connections, and ultrastructure of the nucleus pretectalis superficialis pars magnocellularis (PSm) in carp. J Comp Neurol 336:433-446.

Zuo J, Neubauer D, Dyess K, Ferguson TA, Muir D (1998) Degradation of chondroitin sulfate proteoglycan enhances the neurite-promoting potential of spinal cord tissue. Exp Neurol 154:654-662. 